\title{
A Cadaveric Study on Variations of Branching Patterns of Ulnar Nerve in Hand
}

\section{ABSTRACT}

Introduction: Anatomical knowledge of variations in the branching patterns of ulnar nerve in hand is very important for the surgeons in diagnosis of peripheral neuropathies and in treating nerve compression syndromes. In addition, knowledge of relationship between deep branch of ulnar nerve and deep palmar arch is important in treating ulnar nerve compression due to post-traumatic pseudo aneurysm, true aneurysm of distal ulnar artery or tortuous ulnar artery.

Aim: To observe the division of ulnar nerve in relation to flexor retinaculum, the variations in the branching patterns of ulnar nerve in hand and the relation between deep branch of ulnar nerve and deep palmar arch.

Materials and Methods: An observational study was conducted in 52 cadaveric hands collected from Department of Anatomy, Chettinad Hospital and Research Institute from August 2013 to Dec 2013. Specimens were fixed in $10 \%$ of formalin and dissected. Observations were noted.
Results: Division of ulnar nerve into superficial and deep branch was seen along the middle part of flexor retinaculum in 15 (28.8\%) out of 52 specimens. In $5(9.6 \%)$ out of 52 specimens, this division was seen in the distal part of flexor retinaculum. Trunk of ulnar nerve supplying abductor digiti minimi was seen in $5(9.6 \%)$ specimens and accessory abductor digiti minimi in $3(5.7 \%)$ specimens. Superficial branch of ulnar nerve supplying abductor digiti minimi in five specimens and flexor digiti minimi in three specimens. Deep branch of ulnar nerve was seen along the concavity of deep palmar arch in 15 (28.8\%) specimens and along the convexity in $23(44.2 \%)$ specimens. In 14 (26.9\%) specimens, deep branch of ulnar nerve was seen crossing the deep palmar arch superficially from proximal to distal.

Conclusion: Ulnar nerve presents with many variations in the hand. These variations may lead to entrapment neuropathies which will have varied presentations. Knowledge of these variations will help the general surgeons, orthopedic surgeons and plastic surgeons during various surgical corrections.

\section{INTRODUCTION}

Hand is the important pre-hensile organ which comprises of both extrinsic and intrinsic muscles. Among these, the intrinsic muscles form the major part in hand, majority of these muscles being supplied by the ulnar nerve. Hence, ulnar nerve is considered as musician's nerve which is used for precision movements. The ulnar nerve is formed in the axilla as a continuation of medial cord of brachial plexus. The nerve conveys fibres from $\mathrm{C} 8$ and $\mathrm{T} 1$ and receives the contribution from $\mathrm{C} 7$ through the lateral root of median nerve. Ulnar nerve along with ulnar artery crosses into the palm superficial to flexor retinaculum and on the radial side of pisiform bone. Nerve then divides into superficial and deep terminal branches [1]

Superficial palmar terminal branch supplies the palmaris brevis and divides into medial proper palmar digital nerve and lateral common palmar digital nerve. The proper palmar digital nerve supplies the ulnar side of the little finger and the common digital nerve receives a communicating branch from the nearest palmar digital branch of median nerve and then divides into branches to supply the adjacent side of the little and ring finger [1]. The deep terminal branch passes between the abductor and flexor digiti minimi, pierces the opposing digiti minimi and turns laterally lodging in a groove below the hook of hamate bone and then passes beneath the long flexor tendons to occupy the concavity of the deep palmar arch. Deep branch supplies intrinsic muscles of hypothenar eminence, third and fourth lumbricals, all dorsal and palmar interossei, and adductor pollicis and also supplies the inter-carpal, carpo-metacarpal and metacarpo -phalangeal joints [2].

Anatomical knowledge of variations in the branching patterns of ulnar nerve in hand is very important for the surgeons in diagnosis of peripheral neuropathies and in treating nerve compression syndromes. In addition, knowledge of relationship between deep branch of ulnar nerve and deep palmar arch is important in treating ulnar nerve compression due to post-traumatic pseudo aneurysm, true aneurysm of distal ulnar artery or tortuous ulnar artery [3]. The present study was conducted with the following objectives:

1. To note down the division of ulnar nerve in relation to flexor retinaculum.

2. To observe the variations in the branching patterns of ulnar nerve in hand.

3. To note down the relation between deep branch of ulnar nerve and deep palmar arch.

\section{MATERIALS AND METHODS}

An observational study was conducted in 52 cadaveric hands collected from Department of Anatomy, Chettinad Hospital and Research Institute, Tamil Nadu, India. Study was conducted from August 2013 to Dec 2013. Specimens were fixed in 10\% of formalin and dissected. Dissection of hand was done both in cadavers as well as in disarticulated upper limbs. Specimens were selected irrespective of age, sex and side. Injured hands were excluded from the study. In hand, an incision was made [Table/Fig-1] across the wrist (A). The hand was made open and a longitudinal incision was made across the palm from the center of the wrist to the root of the middle finger ( $A$ to $B$ ). A transverse incision at the level of webs of fingers from second to fifth digit ( $C$ to $D$ ) was then made. The skin was removed from palmar surface of the hands and digits 1 to $5(E)$.

The superficial fascia above the palmar aponeurosis was cleared. Using a scalpel, palmar aponeurosis was removed from the 


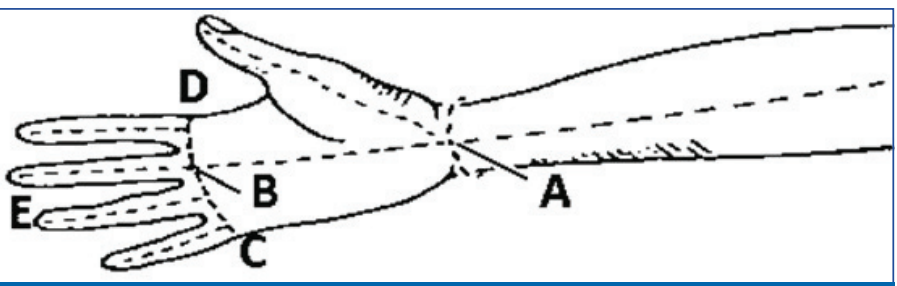

[Table/Fig-1]: Incisions taken during dissection from A-E.

A: Across the wrist; A-B: Longitudinal incision across the palm; C-D: transverse incision at the level of digits; E: Skin of palmar surface of hands and digits

underlying deep structures from proximal to distal direction. Ulnar nerve was found lateral to the pisiform bone. The superficial branch of the ulnar nerve was then dissected. The common and proper digital branches of ulnar nerve were observed. Blunt dissection was made to clean the palmar surface of the hypothenar muscles. The deep branch of the ulnar nerve was seen disappearing beneath the hypothenar muscles [4].

Approximately, $5 \mathrm{~cm}$ proximal to the wrist, the tendons of the flexor digitorum superficialis were transected. The tendons were reflected distally by pulling them through the carpal tunnel towards the digits. Deep to it, the tendons of flexor digitorum profundus were observed along with the four lumbricals attached to it. The deep branch of ulnar nerve was located in the concavity of the deep ulnar arterial arch. The deep branch terminated by supplying the adductor pollicis. Division of ulnar nerve in relation to flexor retinaculum, its branching pattern and relation of deep branch of ulnar nerve with deep palmar arch were observed [4].

\section{STATISTICAL ANALYSIS}

The data was collected in Microsoft Excel sheet and descriptive analysis was done in terms of frequency (n) and percentages (\%).

\section{RESULTS}

Out of 52 hand specimens, 33 showed multiple variations. Division of ulnar nerve into superficial and deep branch was seen along the middle part of flexor retinaculum in 15 specimens (28.8\%). In 5 specimens (9.6\%), this division was seen in the distal part of flexor retinaculum. The bifurcation of ulnar nerve into superficial and deep branch in the guyon's canal is the most common pattern of ulnar nerve branching. This was seen in $84 \%$ of specimens (44 specimens) in the present study. Trunk of ulnar nerve trifurcating into superficial, deep and a muscular branch was seen in eight specimens. Muscular branch supplying abductor digiti minimi was seen in 5 specimens (9.6\%) [Table/Fig-2] and accessory abductor digiti minimi was seen in 3 (5.7\%) specimens [Table/Fig-3].

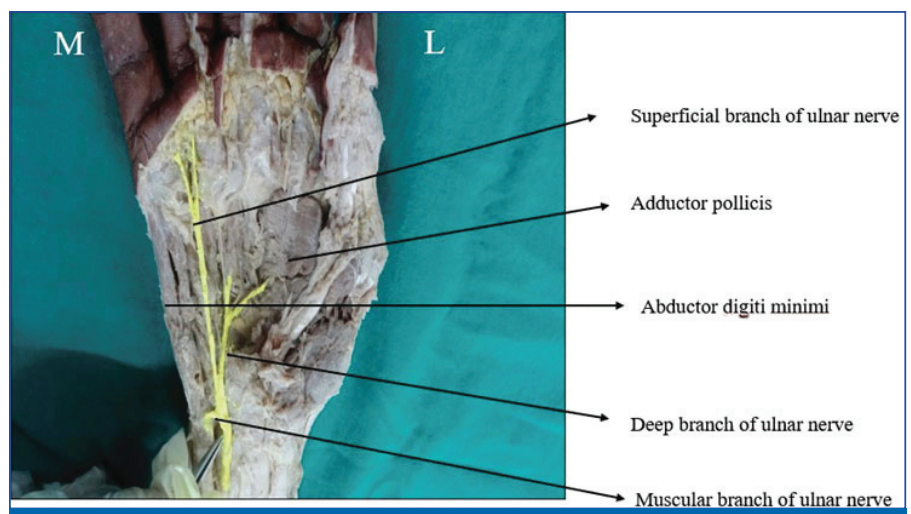

[Table/Fig-2]: Trifurcation of ulnar nerve into superficial, deep and muscular

branch to abductor digiti minimi.

Superficial branch of ulnar nerve supplying Abductor digiti minimi in 5 specimens (9.6\%) [Table/Fig-4] and flexor digiti minimi in 3 specimens (5.7\%) specimens [Table/Fig-5].

Deep branch of ulnar nerve was seen along the concavity of deep palmar arch in 15 specimens (28.8\%) [Table/Fig-6] and along the
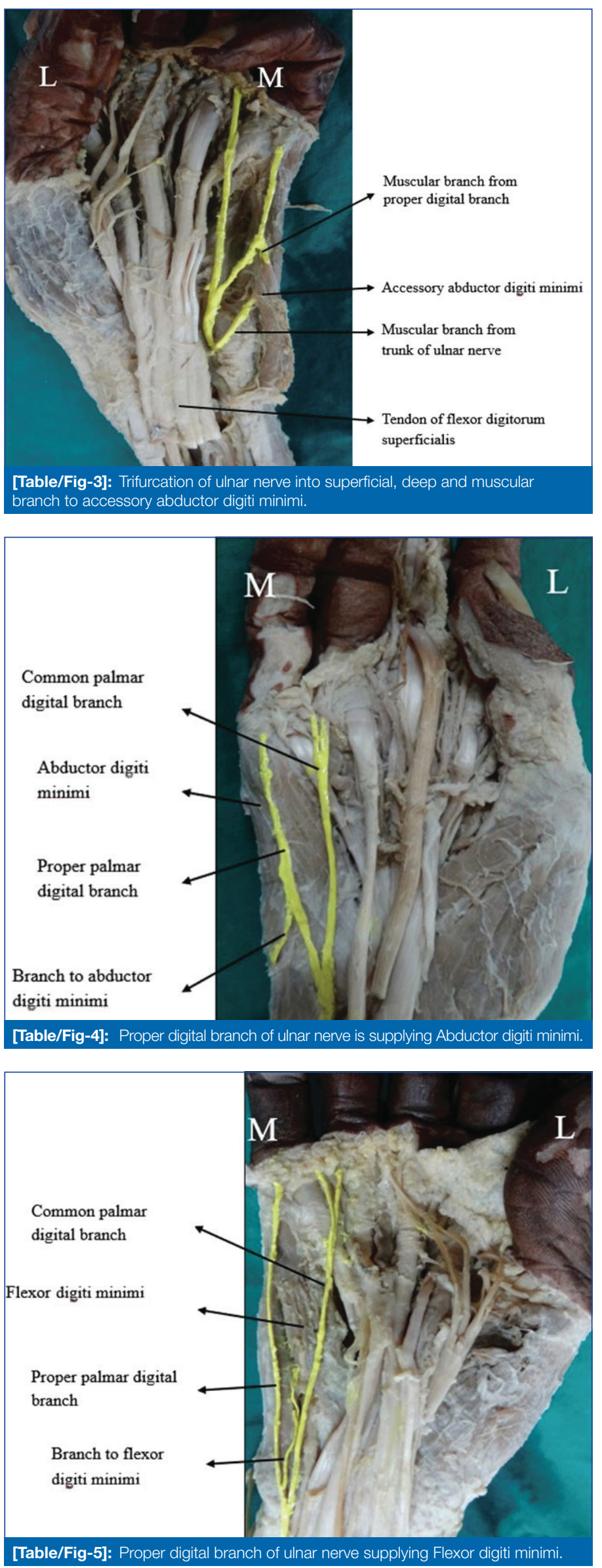

convexity in 23 specimens (44.2\%) [Table/Fig-7]. In 14 specimens (26.9\%), deep branch of ulnar nerve was seen crossing the deep palmar arch superficially from proximal to distal [Table/Fig-8].

\section{DISCUSSION}

Variations in the branching patterns of ulnar nerve in hand are more common than median nerve variations. These variations 

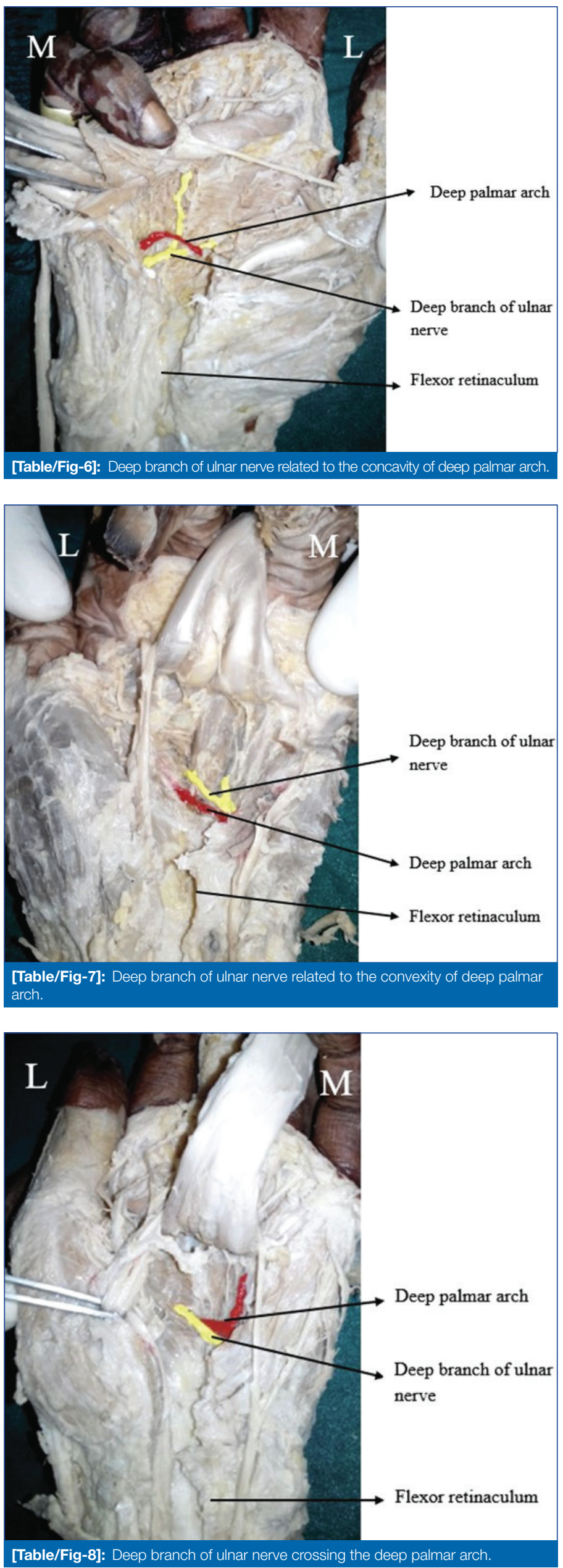

are encountered in clinical practice by the surgeons as well as in cadaveric dissection. In 8 (15.3\%) specimens, the trunk of ulnar nerve trifurcated into superficial, deep and a muscular branch.
In five specimens, the muscular branch supplied Abductor digiti minimi and in three specimens it supplied accessory abductor digiti minimi. Anomalous abductor digiti minimi might compress the ulnar nerve causing neuropathies [5]. In the study conducted by Bonnel $\mathrm{F}$ and Vila RM, the bifurcation pattern was seen in $78 \%$ and rest of the specimens, the trifurcation was seen as the trunk dividing into superficial, deep and a sensory branch unlike in the present study where the third branch of the trunk was the muscular branch [Table/ Fig-9] [6-10]. In the study done by Svenna HWL et al., bifurcation was seen in $72 \%$ and trifurcation in $22 \%$ [11].

\begin{tabular}{|l|c|c|}
\hline Studies & $\begin{array}{c}\text { Bifurcation in } \\
\text { percentages (\%) }\end{array}$ & $\begin{array}{c}\text { Trifurcation in } \\
\text { percentages (\%) }\end{array}$ \\
\hline Bonnel F and Vila RM (1985) [6] & 76 & 22 \\
\hline Lindsey J T and Watermull D (1996) [8] & 81 & 19 \\
\hline Murata Ket al., (2004) [9] & 86 & 14 \\
\hline Ghabriel MN and Makar PH, (2011) [7] & 78 & 22 \\
\hline Mamoru Niitsu et al., (2010) [10] & 70 & 30 \\
\hline Present study & 84 & 15.3 \\
\hline
\end{tabular}

[Table/Fig-9]: Comparison of bifurcation and trifurcation of ulnar nerve in hand with other studies $[6,8,10-12]$

The superficial branch of ulnar nerve gives sensory innervation to medial one and a half digits through proper and common palmar digital nerves. In present study, the superficial branch was also found to supply the muscles on the medial side of hand. Variations in the branching pattern of ulnar nerve especially the trifurcation has to be kept in mind during various decompression procedures at the wrist. Compression of superficial branch of ulnar nerve in the guyon's canal may not only present with neuropathies but also can cause muscular weakness [11].

\section{Limitation(s)}

We could conduct this study in only limited number of cadaveric specimens.

\section{CONCLUSION(S)}

Nerve variations can cause various clinical symptoms, it is therefore important to have detailed anatomic knowledge of the corresponding region. The findings can assist in the diagnosis and treatment of different pathologies affecting the hand such as compression of the ulnar nerve in the Guyon's canal, Dupuytren's contracture and trauma. These details are particularly useful in surgery, orthopaedic practice and plastic surgery procedures. Surgeons and anatomists should be aware of the fact that although the superficial branch of ulnar nerve is sensory, it can also be motor in function and this can be of use while performing hand surgeries and surgical correction of Dupuytren's contracture. Further cadaveric studies with a greater number of specimens are needed which can be combined with radiological studies which will aid the clinicians during surgery.

\section{REFERENCES}

[1] Datta AK, Essentials of Human Anatomy (Superior and inferior extremities). $4^{\text {th }}$ ed. Current Books International; 2010. pp. 104

[2] Stranding S, Ellis H, Healy JC, Johnson D, Williams A, Collins P. Gray's Anatomy - Anatomical basis of clinical practice. $40^{\text {th }}$ ed. Edinburgh: Churchill Livingstone; 2005. pp. 897-898.

[3] Aulicino PL, Hutton PM, Du Puy TE. True palmar aneurysms--a case report and literature review. J Hand Surg Am. 1982;7(6):613-16.

[4] Rachel Koshi. Cunningham's manual of practical anatomy Vol 1. $16^{\text {th }}$ ed. Oxford university press; 2017. pp 26, 95, 101, 105, 110.

[5] Faher M, Millroy P. Ulnar compression neuropathy due to an anomalous abductor digiti minimi. J Hand Surg. 1981;6(3):266-68.

[6] Bonnel F, Vila RM. Anatomical study of the ulnar nerve in the hand. J Hand Surg Br. 1985;10(2):165-68.

[7] Ghabriel MN, Makar PH. Anatomical variations in the ulnar nerve and hypothenar muscles. Int J Anat Var. 2011;4:131-33.

[8] Lindsey JT, Watumull D. Anatomic study of the ulnar nerve and related vascular anatomy at Guyon's canal: A practical classification system. J Hand Surg Am. 1996;21(4):626-33. 
[9] Murata K, Tamai M, Gupta A. Anatomic study of variations of hypothenar muscles and arborization patterns of the ulnar nerve in the hand. J Hand Surg (Am). 2004:29(3):500-09.

[10] Niitsu M, Kokubo N, Nojima S. Variations of ulnar nerve in Guyon's canal: In vivo demonstration using ultrasound and 3T MRI. Acta Radiol. 2010;51(8):939-46.
[11] Verhiel SHWL, Hooven DV, Garg R, Gottlieb REW, Ritt MJPF, Chen NC, et al. Pattern of Ulnar nerve arborization in the palm: Clinical implications for nerve decompression in the hand and wrist. Journal of Hand Surgery Global Online. 2019;1(1):21-27.

[12] Olave E, Prates JC, Del Sol M, Gabrielli C. Anatomocal relationships between the deep palmar arch and deep branch of ulnar nerve. Folia Morphologica. 1997;56(3):187-93.

PARTICULARS OF CONTRIBUTORS:

1. Tutor, Department of Anatomy, Dr Chandramma Dayananda Sagar Institute of Medical Education and Research, Devarakaggalahalli, Kanakapura Road, Karnataka, India.

2. Associate Professor, Department of Anatomy, Jagadguru Gangadhar Mahaswamigalu Moorsawirmath Medical College, Hubballi, Karnataka, India.

NAME, ADDRESS, E-MAIL ID OF THE CORRESPONDING AUTHOR:

\section{Dr. BR Chaitra,}

Associate Professor, Department of Anatomy, Jagadguru Gangadhar

Mahaswamigalu Moorsawirmath Medical College, Kotagondhunsi,

Hubballi-580028, Karnataka, India.

E-mail: drchaitrabr@gmail.com

\section{AUTHOR DECLARATION:}

- Financial or Other Competing Interests: None

- Was Ethics Committee Approval obtained for this study? NA

- Was informed consent obtained from the subjects involved in the study? NA

- For any images presented appropriate consent has been obtained from the subjects.
PLAGIARISM CHECKING METHODS: [Jain Het al.]

- Plagiarism X-checker: Dec 03, 2020

- Manual Googling: Jan 14, 2021

- iThenticate Software: Feb 18, 2021 (17\%)
ETYMOLOGY: Author Origin

Date of Submission: Dec 02, 2020

Date of Peer Review: Jan 06, 2020

Date of Acceptance: Jan 14, 2021

NA 